\title{
Perspectiva estratégica da sustentabilidade nas universidades federais da região nordeste do Brasil: uma análise por meio do triple bottom line
}

Aline Eggres Castro

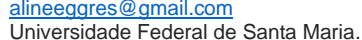
Santa Maria. Rio Grande do Sul. Brasil.

\section{Ana Amélia Moura Zwicker}

ana.ameliamz@gmail.com

Universidade Federal de Santa Maria.

Santa Maria. Rio Grande do Sul. Brasil.

\section{Jordana Marques Kneipp}

jordana.kneipp@ufsm.br

Universidade Federal de Santa Maria.

Santa Maria. Rio Grande do Sul. Brasil.

\section{Mauri Leodir Löbler}

mllobler@gmail.com

Universidade Federal de Santa Maria. Santa Maria. Rio Grande do Sul. Brasil.

\section{RESUMO}

O objetivo do estudo é examinar a perspectiva da sustentabilidade, por meio das dimensões ambiental, social e econômica, nos Planos de Desenvolvimento Institucional (PDIs) das universidades federais (UFs) da região nordeste do Brasil. A pesquisa é qualitativa e de natureza exploratória, operacionalizada por meio de uma pesquisa documental. A técnica de pesquisa foi a análise de conteúdo, com categorização a posteriori dos dados obtidos a partir da Missão, Visão e Valores de 16 UFs da região. Os resultados apontam que a dimensão social da sustentabilidade é amplamente abordada nas diretrizes estratégicas das UFs analisadas, indicando boas perspectivas da atuação do papel das Intituições de Ensino Superior como instrumentos de transformação. A dimensão econômica é moderadamente abordada, sendo mencionada de forma indireta, como o desenvolvimento dos profissionais e da região. A dimensão ambiental, é superficialmente abordada nas diretrizes estratégicas das UFs, indicando área de preocupação para o alcance do desenvolvimento sustentável.
\end{abstract}

PALAVRAS-CHAVE: Sustentabilidade nas Universidades; Educação para a Sustentabilidade; Desenvolvimento Regional; Região Nordeste; Plano de Desenvolvimento Institucional. 


\section{INTRODUÇÃO}

Quando se trata do tema sustentabilidade, um dos aspectos que tem ganhado maior importância se refere à preocupação com a educação que as novas gerações têm em relação aos desafios contemporâneos enfrentados pelo mundo. Nesse contexto, as instituições de ensino, em especial, as de ensino superior - IES, que interagem com jovens com maturidade suficiente para compreender e desenvolver ações em prol do desenvolvimento sustentável, possuem papel fundamental na disseminação de uma cultura que inclua todos os aspectos da sustentabilidade na vivência dos alunos.

As universidades assumem uma responsabilidade fundamental para contribuir com a sustentabilidade e orientar a sociedade no caminho de um futuro sustentável (WAAS et al., 2010). Observa-se nas IES uma crescente preocupação com a inserção dos princípios da sustentabilidade nas suas diretrizes estratégicas e planejamentos institucionais, a fim de incorporar tal realidade nos seus objetivos. Desta forma, o presente estudo propõe uma análise das diretrizes estratégicas e documentos relacionados, disponíveis nos sítios das IES selecionadas para o estudo, a fim de identificar se a sustentabilidade está sendo abordada a nível estratégico por todas elas.

Para o estudo, focou-se nas instituições de ensino superior de natureza administrativa federal que devem atender ao princípio da transparência da administração pública e divulgar os seus relatórios de gestão. $O$ nível universitário foi selecionado, pois de acordo com o Ministério da Educação (MEC, 2017a), "as universidades se caracterizam pela indissociabilidade das atividades de ensino, pesquisa e extensão" e "são instituições pluridisciplinares de formação (...) mediante o estudo sistemático dos temas e problemas mais relevantes, tanto do ponto de vista científico e cultural quanto regional e nacional" podendo, com isso, abranger diferentes aspectos do tema da sustentabilidade.

Considera-se, portanto, que as Universidades possuem o compromisso de formar agentes de intervenção na sociedade para um desenvolvimento sustentável, para que lidem com as possibilidades existentes e para que busquem criar soluções para os problemas sociais, ambientais e econômicos. Além disso, as universidades federais (UFs) brasileiras são conhecidas pelo seu nível de excelência e costumam configurar o topo de listas de qualidade de ensino, como o Índice Geral de Cursos (IGC) promovido pelo Instituto Nacional de Estudos e Pesquisas Educacionais Anísio Teixeira (Inep) - autarquia federal vinculada ao MEC.

Devido ao grande número de universidades federais existentes no país (um total de $63 \mathrm{UF}$, de acordo com o MEC), para viabilizar a execução do estudo e a fim de atender aos objetivos com qualidade, para esse estudo foram selecionadas as Universidades Federais da região Nordeste, as quais, segundo índices publicados pela Proceedings of the National Academy of Sciences of the United States of America (PNAS), integram a região do país que possuem os piores índices de desenvolvimento sustentável do país, ou seja, aquelas que mais precisariam das intervenções das Universidades. Esses indicadores estão entre os dados que compõem os objetivos de desenvolvimento sustentável das Nações Unidas (ONU) que devem ser alcançados até 2030 (BRELSFORD et al, 2017).

Desse modo, o objetivo do estudo consiste em analisar a perspectiva da sustentabilidade, por meio das dimensões ambiental, social e econômica, nos 
Planos de Desenvolvimento Institucional (PDIs) das universidades federais desta região do Brasil. Com isso, verifica-se se as diretrizes estratégicas destas instituições estão alinhadas para a formação de jovens que poderão disseminar os princípios de sustentabilidade na sociedade.

\section{REFERENCIAL TEÓRICO}

Nesta seção, apresenta-se o referencial teórico da pesquisa com uma contextualização inicial sobre a temática da educação para sustentabilidade e desta em universidades. Posteriormente, demonstra-se o papel das universidades como modelos de gestão em relação ao tema e a importância do Plano de Desenvolvimento Institucional para consecução da sustentabilidade. Após, apresenta-se um panorama da região estudada - Nordeste.

\subsection{Educação para Sustentabilidade}

Segundo Jacobi, Raufflet e Arruda (2011), a educação para a sustentabilidade é uma proposta pedagógica centrada na criticidade dos sujeitos, destinando-se à mudança de comportamento e atitudes, ao desenvolvimento da organização social e da participação coletiva. Essa mudança paradigmática exige novas percepções e valores, gerando um pensamento complexo, aberto às indeterminações, às mudanças, à diversidade, à possibilidade de construir e reconstruir, em um processo contínuo de novas leituras e interpretações, configurando novas possibilidades de ação.

Para Barbieri e Silva (2011), as escolas devem adequar os seus currículos, não com disciplinas específicas de Educação Ambiental, mas incluí-la em todas as oportunidades de ensino, de modo que os docentes sejam capazes de tratar as questões ambientais inter-relacionadas com os temas das disciplinas que ministram. Nas IES, se faz necessária a formação de profissionais específicos como engenheiros, administradores, economistas entre outros, que exercem grande influência sobre o meio ambiente, a fim de fomentar valores sustentáveis para os negócios e a sociedade como um todo em busca de uma economia global inclusiva e sustentável.

Entende-se e ressalta-se a importância da formação para sustentabilidade desde a educação básica, a fim de acompanhar toda a trajetória estudantil dos indivíduos. Porém, o foco deste artigo centra-se no ensino superior, momento acadêmico o qual se espera maior maturidade e conhecimento técnico e científico dos alunos para aplicação prática dos preceitos sustentáveis na sociedade.

Assim, a importância da educação para sustentabilidade no ensino superior parte da visão, proficiência e consciência dos futuros profissionais para inverter a crescente degradação do meio ambiente e instaurar a sustentabilidade planetária (MARCOMIN; SILVA, 2009). O ensino superior tem responsabilidade importante para o desenvolvimento de cidadãos com consciência do seu papel para a construção de um mundo mais sustentável (MARQUES et al., 2017). Em virtude disso, o maior desafio é encontrar uma maneira de ensinar a sustentabilidade como modo de vida, formando líderes em sustentabilidade que reflitam sobre a forma como se vive e as consequências das ações (THOMASHOW, 2014). 
Em uma análise sistemática sobre a sustentabilidade no ensino superior em 63 artigos publicados em revistas internacionais de ensino superior e educação gerencial, entre 2003 e 2013, Figueiró e Raufflet (2015) encontraram que todos os artigos destacam a necessidade de mudanças nos currículos, porém, muito poucos especificam como essa mudança poderia e seria alcançada por meio do design do curso ou paradigmas educacionais explícitos. E quando a introdução da temática é alcançada, esta acontece de forma pontual e superficial, diferentemente do ideal, que deveria acontecer de maneira integrada e interdisciplinar.

Considerando a importância da educação em sustentabilidade no ensino superior e os desafios enfrentados para a sua efetiva implementação, este artigo centra-se no foco estratégico das universidades federais da região nordeste, a fim diagnosticar a situação atual para que sejam propostas futuras medidas integradoras e interdisciplinares para modificação da realidade da região.

\subsection{Sustentabilidade em Universidades}

Tauchen e Brandli (2006) apontam que existem duas correntes de pensamento principais referentes ao papel das IES no tocante ao desenvolvimento sustentável. A primeira destaca a questão educacional como uma prática fundamental para que as IES, pela formação, possam contribuir na qualificação de seus egressos, futuros tomadores de decisão, para que incluam em suas práticas profissionais a preocupação com as questões ambientais. A segunda corrente destaca a postura de algumas IES na implementação de sistemas de gestão ambiental em seus campi universitários, como modelos e exemplos práticos de gestão sustentável para a sociedade, sendo um agente especialmente equipado para liderar o caminho. Pode-se concluir que, na visão dos autores, os papéis principais das IES são focados na educação para a sustentabilidade e na gestão ambiental da organização, sendo, portanto, abordados nesta pesquisa.

O conceito de sustentabilidade organizacional vem sendo comumente operacionalizado por meio de três dimensões: econômica, ambiental e social, ou seja, a partir da visão do Triple Bottom Line (ELKINGTON, 2012). Assim, uma universidade sustentável pode ser entendida como aquela que contribui para minimizar os impactos negativos no ambiente e nas questões sociais e econômicas (VELAZQUES et al., 2006). Ainda, uma universidade sustentável deve agregar a sustentabilidade em todo o currículo, focar a sustentabilidade em pesquisas, contatar outros setores da sociedade, construir uma gestão de campus e operações sustentável, e proporcionar oportunidades para o envolvimento dos estudantes (JACOBI; RAUFFLET; ARRUDA, 2011).

A temática ambiental surgiu na gestão das IES a partir da década de 70 . Foi na década de 90, porém, que a preocupação das IES cresceu, com foco no seu papel educacional e de pesquisa na busca de soluções relacionadas ao meio ambiente e ao desenvolvimento sustentável (TERMIGNONI, 2012). O primeiro documento oficial elaborado por reitores e chanceleres foi a Declaração de Talloires, de 1990. Segundo este documento, as instituições de ensino superior existem para servir e fortalecer a sociedade à qual fazem parte.

Após a Declaração de Talloires, outras declarações que tratam de 
Barcelona (2004); Declaração de Graz (2005); Declaração de Abuja (2009); Declaração de Turim (2009). Em 1992, na Conferência das Nações Unidas sobre o Meio Ambiente e o Desenvolvimento - Rio 92 - as universidades atuaram como atores-chave da sustentabilidade na proposta da Agenda 21.

Além de educar as futuras gerações para a tomada de decisão, as instituições de ensino superior têm função importante na trajetória para um futuro global mais sustentável (JACOBI; RAUFFLET; ARRUDA, 2011). Conforme os autores, tal papel é exercido por meio de três componentes: os espaços de formação, intercâmbio e educação; os espaços de pesquisa e geração de ideias; e as organizações per se, com orçamentos e processos de tomada de decisão.

No que diz respeito ao acompanhamento da efetivação da sustentabilidade nas universidades, há um instrumento denominado UI GreenMetric World University Ranking, o qual foi lançado em 2010, pela Universidade da Indonésia. O objetivo deste ranking é fornecer resultados sobre a condição atual e as políticas relacionadas ao Campus Verde e à Sustentabilidade nas Universidades em todo o mundo (GREENMETRIC, 2017). Entre as universidades federais brasileiras, constam na listagem de 2017: Universidade Federal de Lavras - UFLA (350); Universidade Federal de Viçosa - UFV (1870); Universidade Federal do Rio Grande do Sul UFRGS (3570); Universidade Federal de Santa Catarina (462ㅇ); Universidade Federal de Itajuba (465); Universidade Federal de São Paulo UNIFESP (476o); Universidade Federal do Abc (478ㅇ); Universidade Federal de Pernambuco (598ㅇ). Pode-se verificar que consta nesta lista apenas uma universidade do nordeste.

A tentativa de tornar uma universidade sustentável deve estar considerada nos Planos de Desenvolvimento Institucional, entre outros documentos balizadores. Os atores deste processo são: os gestores de todos os níveis hierárquicos; associações com atividades de ensino, pesquisa e extensão; funcionários; comunidade; entre outros (MARCOMIN; SILVA, 2009). Ou seja, é imprescindível o interesse da cúpula estratégica e o comprometimento de todos os stakeholders envolvidos no processo. Por isso, a importância da realização desta pesquisa em nível de PDIs, por meio da análise da Missão, Visão e Valores das Universidades selecionadas.

\subsubsection{Universidades como modelos de gestão}

A universidade é uma instituição social e como tal exprime a estrutura e o modo de funcionamento da sociedade como um todo. Postos os termos desta maneira, poderia se supor que a universidade seria um reflexo da sociedade e do Estado. Não é, porém, o caso. Por ser uma instituição social diferenciada e definida por sua autonomia intelectual, a universidade pode relacionar-se com o todo da sociedade e com o Estado de maneira conflituosa (CHAUÍ, 2003). Dessa forma, as universidades públicas não precisam reproduzir os padrões insustentáveis que permeiam as diferentes esferas da sociedade - elas podem (e devem) agir de forma diferenciada, questionadora e servir como exemplo para os demais setores.

Cada vez mais estudantes, professores e outros membros da comunidade universitária estão empenhados em ajudar a sociedade a fazer a transição para estilos de vida sustentáveis (VELAZQUEZ et al, 2006). As universidades, quando seguidos pela sociedade. Alshuwaikhat e Abubakar (2008) reforçam esse conceito 
ao afirmar que as universidades podem ser comparadas a pequenas cidades, visto o tamanho, a população, as atividades desenvolvidas, o consumo de energia e materiais, as atividades e as operações em ensino e pesquisa que possuem e podem ocasionar degradação ao meio ambiente.

Silva et al (2015) ao investigar casos de gestão sustentável no âmbito universitário no Brasil e no mundo, percebeu que, na maioria das vezes, encontram-se apenas práticas isoladas. A preocupação de adaptação das universidades em busca de um desenvolvimento sustentável, entretanto, demonstra-se crescente. Tauchen e Brandli (2006) concordam que os casos de gestão ambiental são, na maioria das vezes, práticas isoladas, mas que a preocupação é crescente na adaptação das universidades em busca de um desenvolvimento sustentável, não só no aspecto do ensino, mas de práticas de funcionamento ambientalmente corretas.

Tauchen e Brandli (2006) acreditam que a preocupação na adaptação das universidades em busca de um desenvolvimento sustentável é crescente e que as principais ações que aparecem incorporadas a um sistema de gestão ambiental (SGA) para as IES podem ser resumidas em: Assessoria ambiental, levantamento de impactos ambientais; Gestão de recursos - energia, água, qualidade e conforto térmico; Gestão de resíduos, prevenção da poluição; Construção sustentável; Compras com critérios ambientais; Educação integrando aspectos ambientais; Declarações e relatórios ambientais; Investimentos nos aspectos paisagísticos, recuperação da mata ciliar, criação de espaços verdes; e Sistema de captação de águas pluviais e utilização em sanitários e jardins. Para a realização de tais ações, no entanto, é necessário o planejamento. Nas universidades, o planejamento é frequentemente realizado por meio do PDI, conforme apresentado a seguir.

\subsubsection{Plano de desenvolvimento institucional (PDI) e a incorporação da sustentabilidade na gestão estratégica das UF'S}

O Plano de Desenvolvimento Institucional - PDI é o documento que identifica a IES, no que diz respeito à sua filosofia de trabalho, à missão a que se propõe, às diretrizes pedagógicas que orientam as suas ações, à sua estrutura organizacional e às atividades acadêmicas que desenvolve e/ou que pretende desenvolver. 0 MEC, seguindo diversos dispositivos legais (como Lei № 9.394/1996 (LDB), Decreto n. 5.773/2006, Lei № 10.861/2004, entre outros que tratam de diferentes âmbitos da educação no país e critérios de avaliação), fornece uma série de instruções que orientam a elaboração do PDI.

De acordo com o MEC (2017b), a construção do PDI, elaborado para um período de cinco anos, deverá se fazer de forma livre, para que a Instituição exercite a sua criatividade e a liberdade, no processo de sua elaboração. Entretanto, os eixos temáticos constantes das instruções, devem estar presentes, pois serão tomados como referenciais para as avaliações institucionais futuras. Os "Eixos Temáticos Essenciais" das instruções do PDI e alguns tópicos que cada eixo deve incluir são apresentados de forma resumida no Quadro 1 a seguir. 
Quadro 1 - Eixos temáticos do PDI

\begin{tabular}{|c|c|}
\hline Eixos temáticos & Tópicos que cada eixo deve abordar \\
\hline Perfil institucional & $\begin{array}{l}\text { - Histórico da IES; } \\
\text { - Missão; objetivos e metas (com cronograma); } \\
\text { - Áreas de atuação acadêmica }\end{array}$ \\
\hline $\begin{array}{l}\text { Projeto } \\
\text { Pedagógico } \\
\text { Institucional - PPI }\end{array}$ & $\begin{array}{l}\text { - Inserção regional; } \\
\text { - Princípios filosóficos e técnico-metodológicos das práticas acadêmicas; } \\
\text { - Organização didático-pedagógica; } \\
\text { - Políticas de ensino, pesquisa e extensão; } \\
\text { - Políticas de gestão e Responsabilidade Social da IES }\end{array}$ \\
\hline $\begin{array}{l}\text { Cronograma de } \\
\text { implantação e } \\
\text { desenvolvimento } \\
\text { da IES e dos } \\
\text { cursos }\end{array}$ & $\begin{array}{l}\text { - Dados relativos aos cursos ofertados (presencial e a distância) } \\
\text { - Situação atual dos cursos } \\
\text { - Cronograma de expansão na vigência do PDI para todos os níveis (Graduação; } \\
\text { Sequenciais; Pós-Graduação); Polos de EAD; e Campi e cursos fora de sede. }\end{array}$ \\
\hline $\begin{array}{l}\text { Perfil do corpo } \\
\text { docente }\end{array}$ & $\begin{array}{l}\text { - Composição (titulação, regime de trabalho, experiência); } \\
\text { - Plano de Carreira; critérios de seleção e contratação; procedimentos para } \\
\text { substituição (definitiva e eventual); cronograma e plano de expansão do } \\
\text { corpo docente }\end{array}$ \\
\hline $\begin{array}{l}\text { Organização } \\
\text { Administrativa da } \\
\text { IES }\end{array}$ & $\begin{array}{l}\text { - Estrutura Organizacional, Instâncias de Decisão e Organograma Institucional } \\
\text { e Acadêmico; } \\
\text { - Órgãos Colegiados: competências e composição; } \\
\text { - Órgãos de apoio às atividades acadêmicas. }\end{array}$ \\
\hline $\begin{array}{l}\text { Políticas de } \\
\text { atendimento aos } \\
\text { discentes }\end{array}$ & $\begin{array}{l}\text { - Programas de apoio pedagógico e financeiro (bolsas); } \\
\text { - Estímulos à permanência (programa de nivelamento, atendimento } \\
\text { psicopedagógico). } \\
\text { - Organização estudantil (espaço para participação e convivência estudantil) } \\
\text { - Acompanhamento dos egressos. }\end{array}$ \\
\hline Infraestrutura & $\begin{array}{l}\text { - Infraestrutura física (salas de aula; bibliotecas; laboratórios; instalações } \\
\text { administrativas; sala de docentes; coordenações; área de lazer e outros); } \\
\text { - Recursos tecnológicos e de áudio visual. } \\
\text { - Plano de promoção de acessibilidade e de atendimento diferenciado a } \\
\text { portadores de necessidades especiais; } \\
\text { - Cronograma de expansão da infraestrutura para o período de vigência do PDI. }\end{array}$ \\
\hline $\begin{array}{l}\text { Avaliação e } \\
\text { acompanhament } \\
\text { o }\end{array}$ & $\begin{array}{l}\text { - Procedimentos de auto avaliação institucional em conformidade com a Lei no } \\
10.861 / 2004 \text { (SINAES) }\end{array}$ \\
\hline $\begin{array}{l}\text { Aspectos } \\
\text { financeiros e } \\
\text { orçamentários }\end{array}$ & $\begin{array}{l}\text { - Demonstração da sustentabilidade financeira, incluindo os programas de } \\
\text { expansão previstos no PDI: } \\
\text { - Estratégia de gestão econômico-financeira; planos de investimentos; } \\
\text { - Previsão orçamentária e cronograma de execução ( } 5 \text { anos). }\end{array}$ \\
\hline Anexos & $\begin{array}{l}\text { - Projeto pedagógico do(s) curso(s) solicitado(s) para primeiro ano de vigência } \\
\text { do PDI. }\end{array}$ \\
\hline
\end{tabular}

Fonte: MEC (2017b).

Observa-se que os únicos tópicos associados diretamente aos critérios de sustentabilidade são a "sustentabilidade financeira" alinhada à dimensão econômica, e a "responsabilidade social da IES", descrita como "enfatizar a contribuição à inclusão social e ao desenvolvimento econômico e social da região", que de acordo com a descrição do MEC (2017b) estaria alinhada às dimensões 
social e econômica. Além dos tópicos diretamente relacionados, há tópicos facilmente associáveis com a dimensão social, como o plano de promoção de acessibilidade e de atendimento diferenciado a pessoas com deficiência, as políticas de atendimento aos discentes (apoio pedagógico e financeiro e estímulos à permanência, por exemplo) e o plano de carreira docente.

Os demais itens apesar de não apresentarem relações diretas, podem ser contextualizados de acordo com os interesses de cada organização em desenvolver a sustentabilidade por meio deles. O tópico "recursos tecnológicos e de áudio visual", por exemplo, pode ser abordado pelo viés da tecnologia de informação verde, que incorpora a produção mais limpa, descarte correto, economia de energia, entre outros. A partir do panorama apresentado, é introduzida uma contextualização da região nordeste a fim de demonstrar a emergência do aprofundamento da atuação universitária na temática da sustentabilidade nessa região.

\subsection{Contextualização da Região Nordeste no Âmbito da Temática da Sustentabilidade}

A região escolhida neste estudo é uma das cinco regiões brasileiras conforme a divisão regional estabelecida pelo Instituto Brasileiro de Geografia e Estatística (IBGE). Os estados que a compõem são: Alagoas, Bahia, Ceará, Maranhão, Paraíba, Pernambuco, Piauí, Rio Grande do Norte e Sergipe. A população é de 57,36 milhões de habitantes (IBGE, 2017), sendo a segunda maior do Brasil em quantitativo populacional.

No que diz respeito à contextualização regional no âmbito da temática da pesquisa, apresentam-se os dados do Relatório dos Indicadores de Desenvolvimento Sustentável do Brasil do IBGE de 2015. Este documento se integra ao conjunto de esforços internacionais para concretização das ideias e princípios formulados na Conferência das Nações Unidas sobre Meio Ambiente e Desenvolvimento, realizada no Rio de Janeiro em 1992, no que tange à relação entre meio ambiente, sociedade, desenvolvimento e informações para a tomada de decisões (IBGE, 2015). Ao longo da exposição de cada indicador no relatório, é possível encontrar a explicação da sua relevância para o desenvolvimento sustentável.

Nos Quadros 2, 3 e 4 estão expostos os indicadores "ambiental, econômico e social" que constam de forma regionalizada no relatório (muitos indicadores não foram separados por região). Procurou-se destacar a região foco desta pesquisa frente ao resultado geral do Brasil. Ressalta-se ainda que são estimativas, pois os gráficos apresentados no relatório não informam os quantitativos exatos. 
Quadro 2 - Dados da dimensão ambiental nordeste versus Brasil

\begin{tabular}{|c|c|c|c|c|}
\hline Dimensão & & Indicador & $\begin{array}{c}\text { Situação } \\
\text { Brasil } \\
\text { (estimativa) }\end{array}$ & $\begin{array}{c}\text { Situação } \\
\text { Nordeste } \\
\text { (estimativa) }\end{array}$ \\
\hline \multirow{9}{*}{ AMBIENTAL } & \multirow{3}{*}{ Terra } & Uso de fertilizantes (kg/ha) & 175 & 120 \\
\hline & & Uso de agrotóxicos (kg/ha) & 6,9 & 3,5 \\
\hline & & Terras em uso agrossilvipastoril (\%) & 8 & 0,8 \\
\hline & $\begin{array}{c}\text { Oceanos, } \\
\text { mares e } \\
\text { áreas } \\
\text { costeiras }\end{array}$ & $\begin{array}{l}\text { População residente em áreas costeiras } \\
\text { (\%) }\end{array}$ & 23 & 38 \\
\hline & \multirow{5}{*}{ Saneamento } & $\begin{array}{l}\text { Acesso a abastecimento de água (\%) - } \\
\text { urbano }\end{array}$ & 92 & 92 \\
\hline & & $\begin{array}{l}\text { Acesso a abastecimento de água (\%) - } \\
\text { rural }\end{array}$ & 55 & 40 \\
\hline & & $\begin{array}{l}\text { Acesso a esgotamento sanitário (\%) - } \\
\text { urbano }\end{array}$ & 82 & 72 \\
\hline & & $\begin{array}{l}\text { Acesso a esgotamento sanitário (\%) - } \\
\text { rural }\end{array}$ & 32 & 25 \\
\hline & & $\begin{array}{l}\text { Acesso a serviço de coleta de lixo } \\
\text { doméstico }\end{array}$ & 98 & 95 \\
\hline
\end{tabular}

Fonte: IBGE (2015).

Observa-se no Quadro 2 que as terras para uso agrossilvipastoril perfazem $10 \%$ em comparação ao total nacional e a população residente em áreas costeiras supera em $65 \%$ a estimativa do país. Ainda, o acesso ao abastecimento de água e a esgotamento sanitário é consideravelmente menor no Nordeste.

Quadro 3 - Dados da dimensão econômica nordeste versus Brasil

\begin{tabular}{|l|l|c|c|}
\hline \multicolumn{1}{|c|}{ Dimensão } & Indicador & $\begin{array}{c}\text { Situação } \\
\text { Brasil } \\
\text { (estimativa) }\end{array}$ & $\begin{array}{c}\text { Situação } \\
\text { Nordeste } \\
\text { (estimativa) }\end{array}$ \\
\hline \multirow{2}{*}{ ECONÔMICO } & Produto Interno Bruto per capita (R\$) & 21.000 & 10.000 \\
\cline { 2 - 4 } & Valor do saldo comercial (US\$ FOB) & 3.000 .000 & -11.000 .000 \\
\hline
\end{tabular}

Fonte: IBGE (2015).

Conforme Quadro 3, verifica-se que o saldo comercial do Nordeste se encontra negativo e o PIB mostra-se $47 \%$ menor que o do Brasil como um todo. 0 Quadro 4 apresenta a dimensão social da região estudada. 
Quadro 4 - Dados da dimensão social nordeste versus Brasil

\begin{tabular}{|c|c|c|c|c|}
\hline Dimensão & & Indicador & BR & Nordeste \\
\hline \multirow{21}{*}{ SOCIAL } & \multirow[b]{3}{*}{ População } & Taxa de crescimento da população (2000-2010) (\%) & 1,20 & 1,1 \\
\hline & & Taxa de fecundidade total (\%) & 1,75 & 1,9 \\
\hline & & Razão de dependência de jovens e idosos (\%) & 46 & 51 \\
\hline & \multirow{4}{*}{$\begin{array}{l}\text { Trabalho e } \\
\text { rendiment } \\
\quad 0\end{array}$} & Índice de Gini da distribuição do rendimento * & 0,51 & 0,52 \\
\hline & & $\begin{array}{l}\text { Domicílios particulares permanentes urbanos com } \\
\text { rendimento mensal domiciliar per capita de até } 1 / 2 \\
\text { salário mínimo (\%) }\end{array}$ & 17 & 32,5 \\
\hline & & $\begin{array}{l}\text { Rendimento médio mensal nominal das pessoas de } 15 \\
\text { anos ou mais de idade com rendimento (R\$̦) }\end{array}$ & 1400 & 900 \\
\hline & & $\begin{array}{l}\text { Proporção de mulheres de } 16 \text { anos ou mais de idade, } \\
\text { ocupadas na semana de referência, em trabalhos } \\
\text { formais, }\end{array}$ & 56 & 38 \\
\hline & \multirow{7}{*}{ Saúde } & Esperança de vida ao nascer & 74,5 & 71,9 \\
\hline & & Taxa de mortalidade infantil (por 1000 nascidos vivos) & 16 & 21 \\
\hline & & $\begin{array}{l}\text { Número de estabelecimentos de saúde, por } 1000 \\
\text { habitantes, }\end{array}$ & 0,5 & 0,6 \\
\hline & & Leitos para internação, por 1000 habitantes & 2,25 & 2 \\
\hline & & Postos de trabalho médico, por 1000 habitantes & 3,25 & 2,3 \\
\hline & & $\begin{array}{l}\text { Número total de internações hospitalares por doenças } \\
\text { relacionadas ao saneamento ambiental inadequado, } \\
\text { por } 1000 \text { habitantes }\end{array}$ & 200 & 370 \\
\hline & & $\begin{array}{l}\text { Taxa de incidência de AIDS por ano de diagnóstico, por } \\
1000 \text { habitantes }\end{array}$ & 21 & 14 \\
\hline & \multirow[t]{5}{*}{ Educação } & $\begin{array}{l}\text { Taxa de frequência escolar bruta das pessoas de } 15 \text { a } \\
17 \text { anos de idade (\%) }\end{array}$ & 84 & 83 \\
\hline & & $\begin{array}{l}\text { Taxa de frequência líquida das pessoas de } 15 \text { a } 17 \text { anos } \\
\text { de idade (\%) }\end{array}$ & 55 & 45 \\
\hline & & $\begin{array}{l}\text { Taxa de alfabetização das pessoas de } 15 \text { anos ou mais } \\
\text { de idade (\%) }\end{array}$ & 91 & 82 \\
\hline & & $\begin{array}{l}\text { Proporção de pessoas de } 25 \text { a } 64 \text { anos de idade, com } \\
11 \text { anos de estudo, em relação à população total de } 25 \\
\text { a } 64 \text { anos de idade (\%) }\end{array}$ & 27 & 23 \\
\hline & & $\begin{array}{l}\text { Domicílios particulares permanentes adequados para } \\
\text { moradia (\%) }\end{array}$ & 62 & 46 \\
\hline & \multirow[t]{2}{*}{ Segurança } & $\begin{array}{l}\text { Coeficiente de mortalidade por homicídios, por } \\
100.000 \text { habitantes }\end{array}$ & 28 & 36 \\
\hline & & $\begin{array}{l}\text { Coeficiente de mortalidade por acidentes de } \\
\text { transporte terrestre }\end{array}$ & 22,5 & 22,5 \\
\hline
\end{tabular}

Fonte: IBGE (2015).

*O índice de Gini varia de 0 a 1, sendo "1" o valor de máxima desigualdade e

"0" a perfeita igualdade na distribuição de rendimentos (quando $10 \%$ da população se apropria de $10 \%$ da renda total e assim por diante).

No Quadro 4, entre as desigualdades sociais do nordeste, em comparação ao 
salário mínimo; rendimento médio mensal nominal das pessoas de 15 anos ou mais de idade com rendimento; mulheres de 16 anos ou mais de idade, ocupadas na semana de referência, em trabalhos formais; postos de trabalho médico; internações hospitalares por doenças relacionadas ao saneamento ambiental inadequado; frequência líquida das pessoas de 15 a 17 anos de idade; domicílios particulares permanentes adequados para moradia.

De forma complementar, o Relatório apresenta ainda a dimensão Institucional, a qual os resultados que são destacados do Brasil e Nordeste são, respectivamente: proporção de municípios com legislação específica para tratar da questão ambiental (45\%; 35\%); proporção de municípios com Conselho Municipal de Meio Ambiente ativo (49\%; 29\%); proporção dos municípios que participam de comitês de bacias hidrográficas (68\%; $58 \%)$; proporção de municípios com Fundo Municipal de Meio Ambiente (38\%; 21\%); proporção da população residente em municípios com Agenda 21 Local (48\%; 39\%). Tem-se ainda dados do patrimônio cultural (arqueológico, etnográfico, paisagístico, artes aplicadas, belas artes, histórico), os quais evidenciam que a região foco deste estudo está na segunda posição na quantidade de bens de patrimônio material de todos os tipos, por tipo de livro de tombo, ficando atrás apenas do Sudeste.

Outro relatório do IBGE (2017), que faz uma análise das condições de vida da população brasileira, cita o Nordeste como região que apresenta altos índices de vulnerabilidade dos seguintes grupos: mulheres, pretos ou pardos, jovens e população ocupada menos escolarizada. Além disso, a alta taxa de informalidade do mercado de trabalho desta região se traduz em elevado contingente de trabalhadores sem acesso aos mecanismos de proteção social que estão relacionados à formalização, deixando-os, portanto, mais vulneráveis a situações adversas como, por exemplo, a doenças e à desocupação. Em 2016, 38,8\% dos trabalhadores brasileiros estavam em empregos informais, proporção que especialmente alcançou 54,7\% nesta Região (IBGE, 2017).

Ao se avaliar as desigualdades de renda, os estados e capitais das regiões Norte e Nordeste apresentam os maiores percentuais de população vivendo abaixo da linha da pobreza (com rendimento domiciliar per capita inferior a 5,5 dólares por dia, conforme valor adotado pelo Banco Mundial): Maranhão $(52,4 \%)$, Amazonas $(49,2 \%)$ e Alagoas $(47,4 \%)$. Em todos os casos, a pobreza tem maior incidência nos domicílios do interior dos estados do que nas capitais, o que está alinhado com a realidade global, onde a pobreza está $80 \%$ concentrada em áreas rurais (IBGE, 2017).

Quanto ao Índice de desenvolvimento Humano, as cidades da área estudada ainda têm os menores índices do País, segundo o Atlas do Desenvolvimento Humano no Brasil 2013, divulgado pelo PNUD (Programa das Nações Unidas para o Desenvolvimento), órgão da ONU (Organização das Nações Unidas) (ATLAS BRASIL, 2017). No que diz respeito à seca e estiagem enfrentada pela região, segundo o Ministério da Integração Nacional (MI), entre 1991 e 2012, foram registradas 19.517 ocorrências de estiagem e seca em todo o Brasil, sendo mais de $50 \%$ dos registros estão concentrados nesta região do país (MI, 2017).

Por fim, pode ser citado o estudo publicado na revista PNAS, que congrega indicadores de acesso a serviços e infraestrutura urbana, o qual permite avaliar o quão próximo às cidades estão dos Objetivos de Desenvolvimento Sustentável da Organização das nações Unidas (ONU). Entre as seis regiões metropolitanas menos 
sustentáveis, figura em primeiro lugar a região metropolitana do Agreste, em Alagoas. Antes dela aparecem Macapá, Maceió, Sudoeste Maranhense, Belém e Cariri, ou seja, 4 são do Nordeste (BRELSFORD et al, 2017).

O contexto apresentado serve como base para compreensão das dificuldades enfrentadas pela região, as quais poderiam ser amenizadas a longo prazo, conforme defende-se nesse estudo, por meio do investimento na inserção da temática da sustentabilidade nas universidades. Para examinar se diferentes dimensões da sustentabilidade já estão inseridas nos PDIs das UFs nordestinas, os seguintes procedimentos metodológicos foram aplicados.

\section{METODOLOGIA}

A presente pesquisa caracteriza-se como de abordagem qualitativa e natureza exploratória e foi operacionalizada por meio de uma pesquisa documental, a partir de dados secundários obtidos pela análise do Plano de Desenvolvimento Institucional (PDI) das Universidades localizadas no Nordeste do Brasil.

Dentre as 63 universidades federais classificadas pela Secretaria de Educação Superior (SESU), 18 estão localizadas na região foco deste estudo e foram, portanto, selecionadas para análise. Realizou-se o levantamento de dados das principais diretrizes estratégicas dos PDIs, as quais são expressas por meio da Missão, Visão e Valores das Instituições. Nos documentos que estas diretrizes não estavam explícitas, buscaram-se outras formas de verificação dos planos estratégicos das universidades selecionadas para a pesquisa.

O levantamento de dados, de acordo com Marconi e Lakatos (2017) é a fase da pesquisa realizada com intuito de recolher informações prévias sobre o campo de interesse. Ele se constitui de um dos primeiros passos de qualquer pesquisa científica e é feito de duas maneiras: pesquisa documental (ou de fontes primárias) e pesquisa bibliográfica (ou de fontes secundárias). A pesquisa documental inclui a investigação de documentos escritos, relatórios, livros, revistas, jornais, sites, entre outros.

Para análise dos dados, adotou-se a técnica de análise de conteúdo, que de acordo com Bardin (2016) tem a intenção de compreender a comunicação para além do seu significado imediato. Os estudos iniciais dessa técnica na década de 50 tinham como finalidade a "descrição objetiva, sistemática e quantitativa do conteúdo manifesto da comunicação". Tem como característica a neutralidade e objetividade na análise dos dados investigados (BARDIN, 2016).

Bardin (2016) afirma que com o desenvolvimento da técnica ela não tem mais apenas um alcance descritivo, pois também permite realizar inferências, com ajuda de indicadores, regressando às causas ou aos efeitos das características das comunicações. É, portanto, um método indutivo. De acordo com Marconi e Lakatos (2017), indução é um processo mental no qual, partindo de dados particulares, infere-se uma verdade, não contida nas partes examinadas. O objetivo dos argumentos indutivos é, portanto, levar a conclusões cujo conteúdo é muito mais amplo que o das premissas nas quais se estabeleceram. 


\subsection{Coleta de dados}

A realização da pesquisa dividiu-se em três etapas. Inicialmente, para préanálise e exploração do material (BARDIN, 2016) fez-se uma busca pelos PDIs das 18 Universidades selecionadas. Nesta etapa, verificou-se que duas instituições possuem apenas planos em construção e uma delas possui somente uma versão preliminar publicada em seu site (que foi utilizada na pesquisa). Desta forma, foram selecionadas 16 UFs para análise.

Constatou-se também que nem todos os documentos possuíam as diretrizes estratégicas de forma consolidada: apenas 8 universidades possuíam os três itens "Missão, Visão e Valores"; 4 possuíam "Missão e Visão" e 4 continham apenas a "Missão". Em virtude da falta de padronização dos documentos institucionais, recorreu-se a outras formas para identificação do direcionamento estratégico das universidades que não continham os itens de forma explícita: lema, princípios institucionais, referenciais, objetivos institucionais. O modelo conceitual para análise da pesquisa pode ser visualizado no Quadro 5, bem como uma contextualização das UFs: abrangência (número de alunos matriculados), ano de criação e posição no "Ranking Universitário Folha" que classifica 195 instituições brasileiras (entre públicas e privadas) a partir de indicadores de pesquisa, ensino, mercado, internacionalização e inovação.

Quadro 5 - Apresentação das UFs e Modelo conceitual para análise

\begin{tabular}{|c|c|c|c|c|}
\hline Universidade & $\begin{array}{c}\text { Discentes } \\
\text { (quantitativo } \\
\text { ) }\end{array}$ & $\begin{array}{c}\text { Ano } \\
\text { de } \\
\text { criaçã } \\
0\end{array}$ & $\begin{array}{l}\text { Posição } \\
\text { Ranking }\end{array}$ & Itens para análise \\
\hline $\begin{array}{l}\text { Universidade Federal de } \\
\text { Pernambuco - UFPE }\end{array}$ & 30.837 & 1946 & 110 & Missão, Visão e Valores \\
\hline $\begin{array}{l}\text { Universidade Federal da Paraíba - } \\
\text { UFPB }\end{array}$ & 27.847 & 1955 & 290 & Missão, Visão e Valores \\
\hline $\begin{array}{l}\text { Universidade Federal da Bahia - } \\
\text { UFBA }\end{array}$ & 27.789 & 1946 & 150 & Missão, Visão e Valores \\
\hline $\begin{array}{l}\text { Universidade Federal do Maranhão } \\
\text { - UFMA }\end{array}$ & 26.467 & 1953 & 560 & $\begin{array}{l}\text { Missão e Objetivos } \\
\text { Institucionais }\end{array}$ \\
\hline $\begin{array}{l}\text { Universidade Federal de Alagoas - } \\
\text { UFAL }\end{array}$ & 25.252 & 1961 & 440 & Missão e Visão \\
\hline $\begin{array}{l}\text { Universidade Federal do Rio } \\
\text { Grande do Norte - UFRN }\end{array}$ & 25.166 & 1958 & $22 \circ$ & $\begin{array}{c}\text { Missão, Visão e } \\
\text { Objetivos Institucionais }\end{array}$ \\
\hline $\begin{array}{l}\text { Universidade Federal de Sergipe - } \\
\text { UFS }\end{array}$ & 24.667 & 1963 & 38 & $\begin{array}{c}\text { Missão, Visão e } \\
\text { Objetivos Institucionais }\end{array}$ \\
\hline $\begin{array}{l}\text { Universidade Federal do Ceará - } \\
\text { UFC }\end{array}$ & 23.253 & 1954 & $12^{\circ}$ & Missão, Visão e Lema \\
\hline $\begin{array}{l}\text { Universidade Federal do Piauí - } \\
\text { UFPI }\end{array}$ & 22.488 & 1971 & $52^{\circ}$ & Missão, Visão e Valores \\
\hline $\begin{array}{l}\text { Universidade Federal de Campina } \\
\text { Grande - UFCG }\end{array}$ & 15.884 & 2002 & 400 & Missão, Visão e Valores \\
\hline $\begin{array}{l}\text { Universidade Federal Rural de } \\
\text { Pernambuco - UFRPE }\end{array}$ & 10.550 & 1947 & 680 & Missão, Visão e Valores \\
\hline $\begin{array}{l}\text { Universidade Federal do } \\
\text { Recôncavo da Bahia - UFRB }\end{array}$ & 8.861 & 2006 & $132^{\circ}$ & $\begin{array}{l}\text { Missão e Princípios } \\
\text { Institucionais }\end{array}$ \\
\hline
\end{tabular}




\begin{tabular}{|l|c|c|c|c|}
\hline $\begin{array}{l}\text { Universidade Federal Rural do } \\
\text { Semi-Árido - UFERSA }\end{array}$ & 7.548 & 2005 & 940 & Missão e Objetivos \\
\hline $\begin{array}{l}\text { Universidade Federal da Lusofonia } \\
\text { Afro-Brasileira - UNILAB }\end{array}$ & 6.803 & 2010 & 173 o & $\begin{array}{c}\text { Missão e Princípios } \\
\text { Institucionais }\end{array}$ \\
\hline $\begin{array}{l}\text { Universidade Federal do Vale do } \\
\text { São Francisco - UNIVASF }\end{array}$ & 5.390 & 2002 & 103 ○ & Missão, Visão e Valores \\
\hline $\begin{array}{l}\text { Universidade Federal do Cariri - } \\
\text { UFCA }\end{array}$ & 2.128 & 2013 & 182 o & $\begin{array}{l}\text { Missão, Visão, Valores e } \\
\text { Princípios Institucionais }\end{array}$ \\
\hline
\end{tabular}

Fonte: elaborado pelos autores (2018).

Tal como evidencia o Quadro 5, as Universidades Federais avaliadas não possuem uniformidade em relação às principais diretrizes estratégicas expressas por meio dos PDIs. Em alguns documentos, observa-se certa precariedade e a necessidade de uma maior consolidação a fim de expressar de forma clara e objetiva o direcionamento do desenvolvimento institucional almejado. Ainda, no processo de busca dos documentos institucionais, constatou-se que apenas uma instituição não possui o PDI atualizado no seu Portal: UFBA, sendo desenvolvido para o período de 2012 a 2016. Além disso, 4 instituições não cumprem a indicação de prazo de 5 anos de execução do PDI: UFCG ( 6 anos); UFRN e UNIVASF (10 anos); UFRPE (8 anos).

Das 18 universidades foco da pesquisa, verificou-se que 4 delas foram criadas recentemente, após 2010, a partir do Programa de Apoio a Planos de Reestruturação e Expansão das Universidades Federais (Reuni), que foi instituído pelo Decreto no 6.096, de 24 de abril de 2007, cujo principal objetivo é ampliar o acesso e a permanência na educação superior. O curto período de existência dessas UFs é uma possível explicação porque 2 destas ainda não possuíam o PDI em seu portal: UFSB e UFOB (as quais foram excluídas da pesquisa).

Na segunda etapa, ainda de exploração e tratamento do material foi realizada análise lexical (BARDIN, 2016), com o auxílio do software Nvivo, inicialmente por meio da função "frequência de palavras". O objetivo foi identificar as palavras e termos mais frequentes presentes nos PDIs, as quais deveriam possuir no mínimo 3 caracteres. Nesta fase, foi acionada a função "palavras derivadas" do software, para evitar a repetição de palavras similares (como ambiente e ambiental, por exemplo). Na terceira etapa, utilizou-se a função "visualização de nó" do Nvivo, que demonstra os fragmentos de texto nos quais as palavras estão inseridas, a fim de verificar o contexto no qual elas foram mencionadas e com isso poder fazer as associações e análises semânticas (BARDIN, 2016) corretas com as categorias de análise criadas. A seguir, os dados encontrados são discutidos em relação à situação atual da região Nordeste, a fim de avaliar se as UF estão atendendo às principais demandas que a região necessita para atingir o desenvolvimento sustentável.

\section{ANÁLISE E DISCUSSÃO DOS RESULTADOS}

Neste estudo, foram realizadas as análises lexicais e por categorização a partir das dimensões da sustentabilidade anteriormente apresentadas. Os próximos tópicos expõem os achados encontrados na análise de conteúdo das diretrizes 
de sustentabilidade da região, obtido por meio de informações de relatórios do IBGE.

\subsection{Análise Lexical}

No total, o software Nvivo analisou 909 palavras com 3 ou mais caracteres, reduzidas em 839 termos, devido a semelhanças lexicais provenientes da função "palavras derivadas". Primeiramente foram selecionadas o que Bardin (2016) chama de "palavras plenas" (portadoras de sentido - substantivos, adjetivos, verbos) e descartadas as "palavras instrumento" (função de ligação - artigos, preposições, pronomes, advérbios, conjunções).

Entre as palavras plenas mais citados (mais de 30 vezes) estão "conhecimento", "desenvolvimento" e "missão". A produção e disseminação de conhecimento trata-se da função central das UFs e é nesse sentido que o termo é trazido. A missão é uma diretriz estratégica do PDI e aparece sempre usada como a indicação do propósito da IES. O termo que aparece em diferentes contextos, é "desenvolvimento" - trata-se de diferentes dimensões, mas a maioria associada ao desenvolvimento sustentável, ou a constructos que podem ser relacionados a ele, como apresentado nos fragmentos a seguir.

- "Promover conhecimento crítico e socialmente comprometido para o desenvolvimento territorial sustentável" (UFCA);

- “...tem por missão a sua inserção no desenvolvimento regional socialmente comprometido..." (UFCG);

- "Ministrar ensino superior visando ao desenvolvimento político, científico, social, ambiental e econômico do indivíduo e da sociedade" (UFERSA);

- "Geração e difusão do conhecimento que possa propiciar o desenvolvimento científico-tecnológico, socioambiental, econômico e cultural..." (UFPB);

- "...comprometida com o desenvolvimento socioeconômico, de modo inovador e sustentável" (UFPI);

- "...e contribuir para o desenvolvimento humano, comprometendo-se com a justiça social, a sustentabilidade socioambiental, a democracia e a cidadania" (UFRN);

- “...formação de cidadãos críticos, éticos e comprometidos com o desenvolvimento Sustentável” (UFS).

As seguintes palavras mais frequentes (citadas mais de 15 vezes) são aquelas relacionadas diretamente a atividades acadêmicas - "ensino", "pesquisa", "extensão", "universidade", "instituição", "formação"; além das palavras "valores" e "visão" - diretrizes estratégicas do PDI. Tais termos servem como base temática dos documentos em geral, não oferecendo dados centrais de análise, e sim formas de se alcançar os objetivos. Estão diretamente atrelados a outros termos como "qualidade", "excelência", "referência" a fim de qualificar os termos.

Há grande destaque para os termos "social" (21 menções) e "sociedade" (16 menções), além de outros similares como "socialmente", "socializar" e 
"socialização", que em uma classificação temática poderiam ser somados, formando o tema de maior evidência. Todas as vezes que o tema foi mencionado estava no sentido de melhorar as condições da sociedade, resolver problemas sociais, emancipar os cidadãos e promover a integração da UF com a sociedade a fim de ser um ator de transformação na sociedade. Alguns fragmentos de análise sobre a temática "sociedade" podem ser analisados a seguir.

- "...promoção da democracia, da cidadania, dos direitos humanos, da justiça social e da ética ambiental e profissional..." (UFCG);

- "Ministrar ensino superior visando ao desenvolvimento político, científico, social, ambiental e econômico do indivíduo e da sociedade..." (UFERSA);

- "Comprometimento com a responsabilidade social e sustentabilidade" (UFCA);

- “...baseada em princípios humanísticos, críticos, reflexivos, investigativos, éticos e socialmente responsáveis" (UFMA);

- "Compromisso com a justiça social, equidade, cidadania, ética, preservação do meio ambiente, transparência e gestão democrática" (UFPI);

- “...interação com os poderes públicos, setor produtivo e movimentos sociais de modo a construir uma sociedade mais justa" (UFPB);

- "...participar de transformações que conduzam ao aperfeiçoamento da sociedade por meio de ações extensionistas acionadas por uma gestão universitária competente..." (UFRB);

- "Contribuir para o progresso da sociedade por meio da geração de conhecimento e da formação de cidadãos críticos, éticos e comprometidos com o desenvolvimento sustentável" (UFS);

- “...buscando o desenvolvimento educacional e cultural como via de superação de problemas da sociedade e a promoção do seu bem-estar" (UNIVASF).

As seguintes temáticas de maior destaque foram "cultura" ou "cultural", "respeito" e "diversidade". Observou-se que tais temas estavam intrinsicamente conectados na maioria dos conteúdos analisados, visto que a valorização e o respeito a diversidade de manifestações culturais demonstraram-se como ponto de grande importância para as UFs da região. Tais pontos também foram associados a outras temáticas bastante relevantes ao longo da análise, como "igualdade" e "inclusão", conforme observados nos seguintes fragmentos de análise. 
- “...reconhecimento e respeito à diversidade étnico-racial, religiosa, cultural e, de gênero; inclusão social com qualidade acadêmica..." (UNILAB);

- “...formação vinculada à criação de consciência cidadã, sustentada no respeito aos direitos humanos, à diversidade cultural e à paz mundial..." (UNILAB);

- “...preservar e divulgar os valores éticos, científicos, artísticos e culturais..." (UFC);

- “...de respeito à diversidade cultural como fundamentos de uma convivência social mais igualitária, responsável e justa" (UFPE);

- "Respeito à diversidade de pensamento, assegurando a pluralidade de opiniões; convivência na diversidade, de tal modo que sejam respeitadas as diferenças e as divergências" (UFCG);

- "Reconhecimento das atividades artísticas, culturais e esportivas como fundamentais para a formação da comunidade universitária" (UFCA);

- “... contribuir para a valorização da diversidade e do patrimônio cultural e natural da região..." (UFRB);

- “...buscando o desenvolvimento educacional e cultural como via de superação de problemas da sociedade e a promoção do seu bemestar" (UNIVASF);

- "Respeito às diferenças de gênero, orientação sexual, raça/etnia e credo religioso..." (UFCA);

- “...Equidade; Inclusão; Respeito aos Saberes Populares; Respeito à Diversidade..." (UFRPE);

- "Aprofundamento da relação entre o Ensino, a Pesquisa, a Extensão e a Cultura" (UFCA).

Além da questão cultural, os temas "inclusão" e "igualdade" (ou "equidade") também são fortemente associados a questões históricas e políticas de desigualdade social as quais se deve buscar a superação por meio da atuação das UFs. Esses pontos são evidenciados nos seguintes fragmentos.

- “...inclusão de um público historicamente colocado à margem das políticas de formação para o trabalho, dentre este, as pessoas que residem em localidades geograficamente distantes..." (UFPI);

- “Inclusão Social - manter o compromisso com a inclusão de pessoas e grupos ainda à margem do ensino superior, como consequência de desigualdade, discriminação ou ambas" (UFRB);

- "Ser instrumento de equidade social, ofertando vagas indistintamente às diferentes camadas da população..." (UFS);

- “...integração com o meio, como forma de contribuir para a superação das desigualdades sociais e econômicas, por meio da promoção do desenvolvimento sustentável do Ceará..." (UFC); 
- “...por meio da formação de cidadãos com sólido conhecimento técnico, científico e cultural e compromissados com a necessidade de superação das desigualdades sociais..." (UNILAB).

De maneira geral, o foco central do conteúdo das diretrizes estratégicas das UFs analisadas está voltado para as questões de desenvolvimento social e superação de problemas locais e regionais (ênfase na dimensão econômica da sustentabilidade). Algumas incluem o âmbito nacional, mas poucas UFs demonstram uma noção mais ampla da sustentabilidade incluindo a visão global de suas ações. Além disso, a maior parte do conteúdo tem viés tecnicista, tratando o aluno formado como um "produto" ou um "recurso", e com discurso padrão da promoção do conhecimento e desenvolvimento da região por meio das atividades de ensino, pesquisa e extensão.

O viés tecnicista é observado especialmente nas UFs mais antigas, enquanto o caráter regionalizado é visto especialmente nas UFs do interior, que tem o propósito específico de desenvolver essas regiões, justificando suas falas. No entanto o caráter territorial restrito também é visto em UFs tradicionais localizadas em capitais, como UFBA, UFMA e UFPI, que colocam sua missão como "local, regional e nacional". A seguir, pode-se observar alguns exemplos da visão restrita e tecnicista que algumas UFs têm de sua atuação.

- “...situar-se como centro dinâmico de desenvolvimento local, regional e nacional..." (UFMA);

- "...tendo em vista a melhoria contínua dos produtos devolvidos à sociedade..." (UFBA);

- "...formando recursos que contribuam para o desenvolvimento econômico, político, social e cultural local, regional e nacional" (UFPI);

- “...produzir e difundir conhecimentos no campo da educação superior, com ênfase na região semiárida brasileira" (UFERSA);

- “...formação de cidadãos dotados de competência técnica, científica e humanística e que valorizem as culturas locais e os aspectos específicos e essenciais do ambiente físico e antrópico (UFRB);

- "Visão para 2020: Consolidar-se no âmbito regional como universidade pública de excelência" (UFRPE);

- "Formar recursos humanos de nível superior, em graduação e pósgraduação, para atender às necessidades locais, regionais e nacionais; estimular a elevação do desempenho institucional, alocando e valorizando recursos humanos e viabilizando recursos materiais para isso necessários" (UFS);

- "Como instituição pública, promover a formação de pessoas e a construção de conhecimentos e competências científicas e técnicas..." (UFPE);

Há, no entanto, outras UFs tradicionais que tornaram seu discurso mais contemporâneo e alinhado às realidades complexas da sustentabilidade e da globalização. As UFs mais jovens, já criadas sob esses paradigmas também incorporam esses pensamentos em suas diretrizes estratégicas. Atenção especial nesse sentido à UNILAB que surgiu em 2010 com a função de integração entre o 
Brasil e os demais países membros da Comunidade dos Países de Língua Portuguesa (CPLP), especialmente os países africanos, ou seja, já foi pensada desde sua constituição no caráter internacional.

Por fim, a dimensão ambiental da sustentabilidade é apenas mencionada nas diretrizes estratégicas das UFs, como se fizesse parte de um "check list" de itens que devem ser citados no texto. Em nenhum PDI analisado há o desenvolvimento da questão ambiental nas principais diretrizes estratégicas. Alguns exemplos podem ser visualizados nos seguintes fragmentos de análise.

- "Preservação do meio ambiente e construção de espaços sustentáveis de convivência" (UFCA);

- “..comprometida com o desenvolvimento sustentável, com a promoção da democracia, da cidadania, dos direitos humanos, da justiça social e da ética ambiental e profissional" (UFCG);

- “...solução dos problemas sociais, ambientais, econômicos e políticos, dando ênfase à região Semiárida brasileira" (UFERSA);

- “...compromisso com a justiça social, equidade, cidadania, ética, preservação do meio ambiente, transparência e gestão democrática” (UFPI)

- “...compromissados com a necessidade de superação das desigualdades sociais e a preservação do meio ambiente" (UNILAB);

- "...exigências de responsabilidade moral, de cuidado com o meio ambiente..." (UFPE);

- "Seu trabalho deve contribuir para a valorização da diversidade e do patrimônio cultural e natural da região..." (UFRB).

É válido ressaltar que o discurso nas diretrizes estratégicas não está diretamente ligado ao desempenho das IES, visto que UFs que se destacam em sua visão ampla da sustentabilidade ainda possuem desempenho baixo em avaliações institucionais (como UNILAB e UFCA) enquanto UFs de maior destaque acadêmico como a UFBA sequer possui o PDI atualizado. Com a análise semântica dos conteúdos selecionados as três macro categorias inicialmente definidas foram gradualmente recebendo categorias intermediárias e micro categorias conforme foram identificados temas relacionados a elas. O resultado dessa categorização e as discussões sobre a contextualização com a situação da região estudada são apresentados a seguir.

\subsection{Categorização do Triple Bottom Line}

Definiu-se a priori a segmentação em macro categorias temáticas (BARDIN, 2016), balizadas nos três pilares da sustentabilidade: social, econômico e ambiental (ELKINGTON, 2012). A partir das macro categorias foram desdobradas categorias intermediárias e micro categorias ao longo do processo de análise, buscando identificar a presença de diretrizes estratégicas relacionadas ao tema da sustentabilidade - categorização com grade mista (VERGARA, 2005), quando porém admite-se a inclusão de categorias surgidas durante o processo de análise. 
Verifica-se a necessidade de subdivisão, inclusão ou exclusão de categorias e estabelece-se o conjunto final de categorias, considerando o possível rearranjo.

As três dimensões do Triple Bottom Line de Elkigton (2012) consideradas para análise foram "social" (sustentabilidade ao longo do tempo por meio da relação de transparência que a organização mantém com os seus consumidores, e das ações praticadas na sociedade, incluindo o capital humano, o desenvolvimento de habilidades e a educação, além de medidas de saúde da sociedade como um todo e o potencial de geração de riquezas); "econômica" (sustentabilidade econômica da organização ao longo do tempo, incluindo o capital natural, social, humano e intelectual); e "ambiental" (a riqueza natural que sustenta o ecossistema - capital natural: crítico e renovável).

Para a etapa de tratamento dos resultados e interpretações (BARDIN, 2016) os dados categorizados foram apresentados, por ordem de maior frequência, em fragmentos de análise que demonstram o conteúdo semântico dos principais temas abordados nas diretrizes estratégicas dos PDIs das UFs analisadas.

\subsubsection{Macro categoria social}

O pilar social da sustentabilidade demonstrou-se o mais evidente no conteúdo das diretrizes estratégicas das UFs analisadas, logo foi o que gerou mais categorias intermediárias e micro categorias, conforme observa-se na Figura 1.

Figura 1 - Categoria Sustentabilidade Social

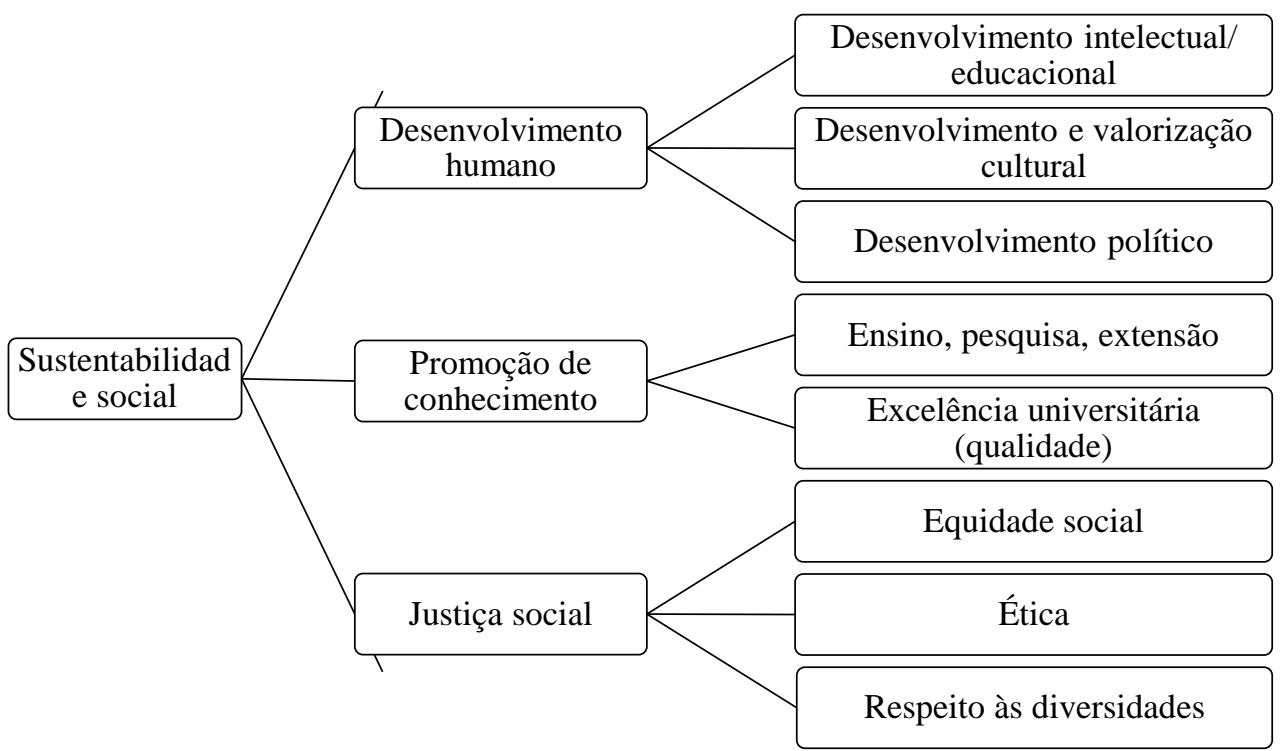

Fonte: dados da pesquisa (2017).

Avaliando a situação regional, conforme abordado na segunda seção desse estudo, observa-se que o foco dado pelas UFs na questão da promoção da justiça social por meio da equidade e respeito às diversidades é bastante coerente com as dificuldades presentes na região. As desigualdades são visíveis ao analisar os dados relativos à distribuição de renda; presença feminina reduzida no mercado de trabalho; informalidade de empregos; menor nível de escolaridade da população ocupada; índices de saúde, higiene e saneamento bastante inferiores à média nacional; entre outros. Ressalta-se também a grande importância que as 
UFs demonstram à natureza pública e a gratuidade dos cursos como critério tanto de inclusão quanto de excelência. Isso está de acordo com os dados que indicam os baixos níveis de renda da população que necessita da IES gratuita para possuir o acesso ao ensino.

Outro ponto de destaque no conteúdo analisado foi a ênfase a valorização e respeito à cultura local. Esse ponto também está de acordo com os dados encontrados, visto que a região se encontra na segunda posição nacional de quantidade de bens tombados como patrimônio cultural. A cultura é claramente um tema de grande relevância para a região e é utilizado pelas UFs como forma de valorizar a identidade regional, promovendo a inclusão e o desenvolvimento econômico local por meio do turismo. A questão econômica da sustentabilidade é discutida a seguir.

\subsubsection{Macro categoria econômica}

O pilar econômico da sustentabilidade é abordado de forma mais indireta nas diretrizes estratégicas analisadas. Para contemplar o pilar econômico da sustentabilidade, construiu-se a macro categoria apresentada a seguir, na qual se identificaram três categorias intermediárias (Figura 2).

Figura 2 - Categoria Sustentabilidade Econômica

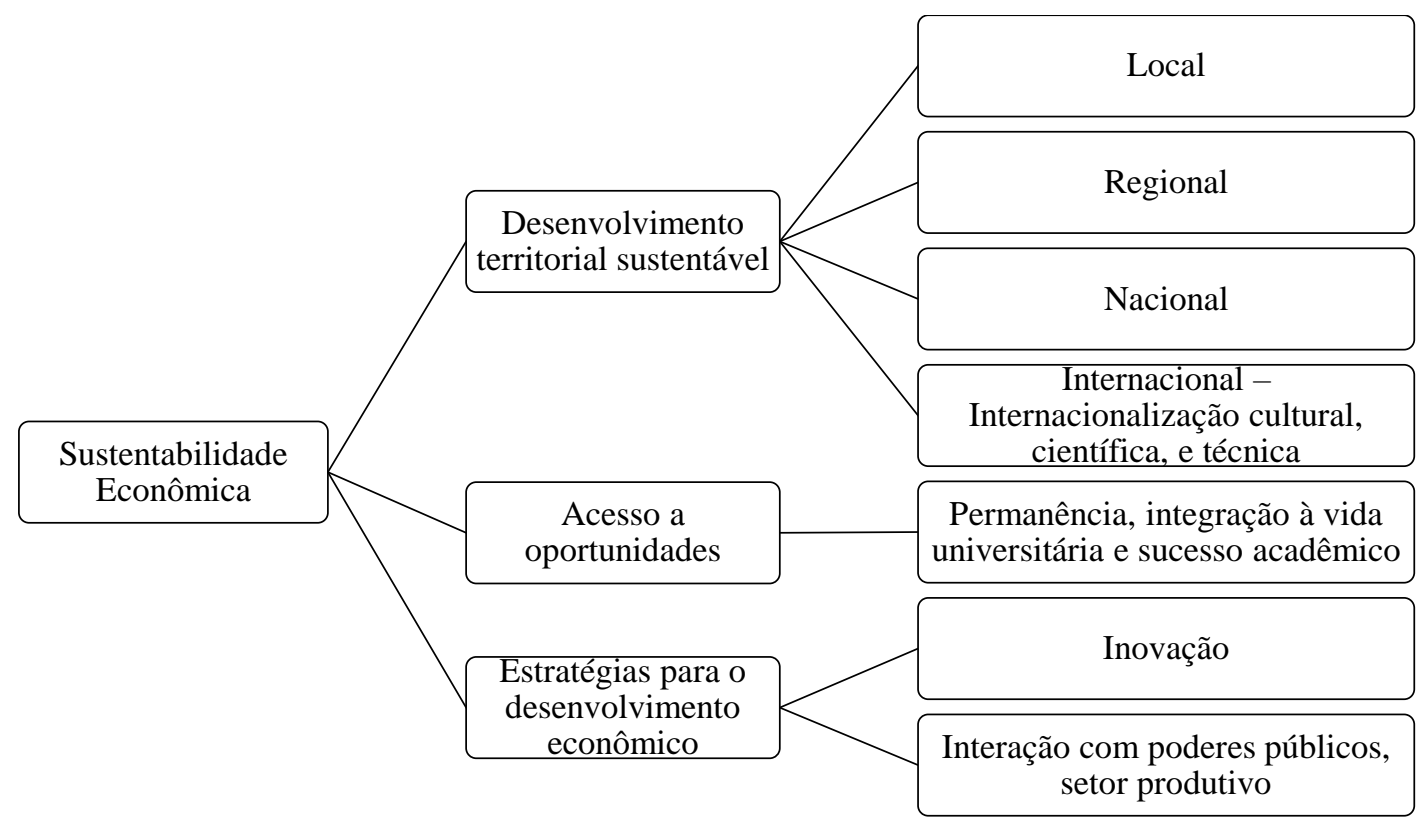

Fonte: dados da pesquisa (2017).

O desenvolvimento econômico local e regional é bastante enfatizado nos PDIs analisados, tendo em vista que o PIB da região é o mais crítico do Brasil (IBGE, 2015). Uma das formas de promover esse desenvolvimento é por meio da formação de profissionais capacitados (o que também colaboraria com o desenvolvimento nacional e internacional), por meio do acesso à universidade pública gratuita, com benefícios socioeconômicos que auxiliem a permanência ao longo do curso. Os egressos capacitados também devem ser fonte da promoção da inovação para solução dos problemas locais, que se perpetuam ao longo dos anos, logo necessitam de novos olhares diferenciados, aliando as atividades das UF 
com as potencialidades dos diferentes setores produtivos e o auxílio necessário dos setores públicos.

Outra questão bastante mencionada é o do desenvolvimento cultural, que pode ser vista por meio do viés social, como analisado anteriormente, e também pelo ponto de vista econômico por meio de atividades de turismo. O desenvolvimento territorial regional também é enfatizado em função da atividade econômica produtiva, visto que na maioria dos estados do Nordeste menos de $10 \%$ das terras são destinadas ao uso agrosisilvipastoril. Apenas em Alagoas e Sergipe essa porcentagem se aproxima aos 20\% (IGBE, 2015). Tais dificuldades se dão em grande parte pelas condições climáticas e de vegetação da região, conforme analisado a seguir.

\subsubsection{Macro categoria ambiental}

A dimensão ambiental foi a dimensão abordada de forma mais superficial nos documentos analisados, por isso ela gerou menos categorias de análise que as dimensões anteriores, conforme Figura 3.

Figura 3 - Categoria Sustentabilidade Ambiental

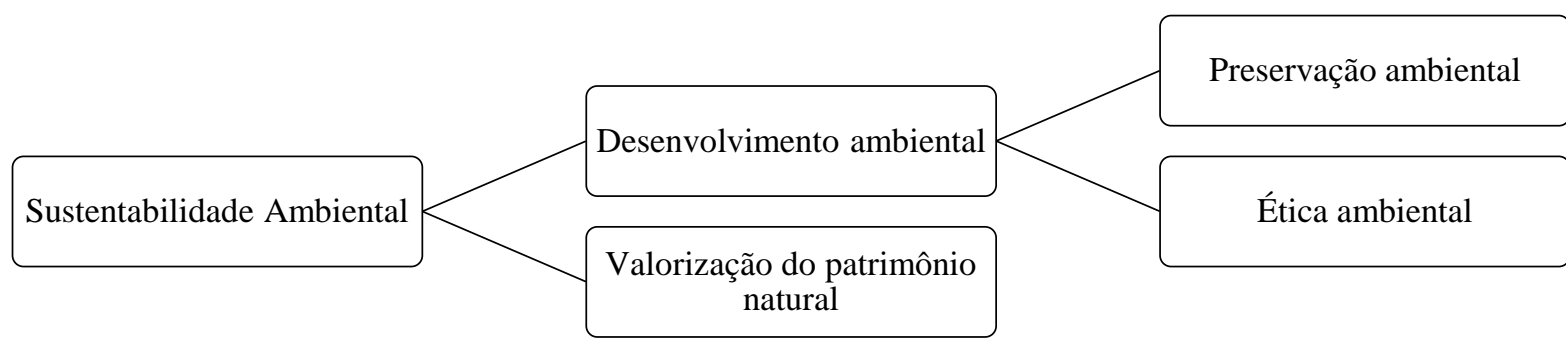

Fonte: dados da pesquisa (2017).

Os problemas ambientais na região analisada estão intrinsicamente relacionados ao clima e a vegetação do local, que dificultam a disseminação de diversas atividades econômicas devido às secas que devastam grandes áreas. 0 acesso ao abastecimento de água é bastante inferior à média nacional, gerando diversas dificuldades que diminuem a qualidade de vida da população, em questões como saneamento, alimentação, moradia (aglomerações nas áreas costeiras), entre outros.

O grande contingente de população na zona costeira, associados à carência de saneamento ambiental, especialmente de coleta e tratamento de esgotos domésticos e industriais, causam impactos sobre o meio ambiente, afetando a qualidade da água no litoral, a pesca e a atividade turística, a redução das áreas de restinga e manguezal. Além disso, a população residente na área costeira está entre as que mais serão afetadas pelas mudanças ambientais associadas ao efeito estufa, entre as quais a elevação do nível do mar, com submersão de parte do litoral (IBGE, 2015).

Devido à gravidade dos problemas, considera-se que a dimensão ambiental deveria receber grande destaque nos debates acadêmicos, políticos e sociais da região. No entanto, o problema não é abordado de forma apropriada pelos PDIs baixa prioridade dada à questão na região de uma maneira geral. Os dados 
apresentados na seção dois, indicam que uma parcela pequena dos municípios da região possui legislações, conselhos e fundos para tratar de questões ambientais.

Considera-se muito importante, portanto, que as UFs desenvolvam de forma mais profunda os termos que colocam apenas de forma sistemática em seus PDIs, relacionados à temática ambiental e disseminem tais conteúdos nas IES e na sociedade. A solução dos problemas ambientais está associada ao conhecimento e desenvolvimento de ações em relação a eles e as UFs seriam um ponto de partida na busca por essas soluções.

\section{CONSIDERAÇÕES FINAIS}

As inúmeras dificuldades enfrentadas pela região Nordeste enfatizam a demanda por estudos que busquem promover o desenvolvimento sustentável da região por meio de diferentes abordagens. $O$ enfoque dado por esse estudo é o papel das instituições de ensino superior de natureza pública federal na intervenção nos principais problemas sociais, econômicos e ambientais e a promoção de estratégias de modificação da realidade local.

Desse modo, o objetivo do estudo foi analisar a perspectiva da sustentabilidade, por meio das dimensões ambiental, social e econômica, nos Planos de Desenvolvimento Institucional (PDIs) das universidades federais desta região do país. A partir da metodologia utilizada, foi possível verificar se as diretrizes estratégicas destas instituições estão alinhadas com os princípios de sustentabilidade na sociedade.

Os resultados do estudo apontam que a dimensão social da sustentabilidade, que apresenta grandes desafios nesta região, é amplamente abordada nas diretrizes estratégicas das UFs analisadas, indicando boas perspectivas da atuação do papel das IES como instrumentos de transformação. A principal forma que as UFs encontram para transformação da realidade social é por meio do desenvolvimento humano - fomentando a democracia e o pensamento crítico elas podem enfatizar mais a necessidade de o cidadão conhecer os seus direitos e lutar por eles. As instituições de ensino possuem o papel de ser disseminadoras de ideais de cidadania que permitam aos indivíduos exercer seu papel político.

A dimensão econômica é moderadamente abordada, sendo mencionada de forma indireta, como o desenvolvimento dos profissionais e da região. Sugere-se considerar nos documentos institucionais das Universidades o planejamento de ações de intervenção mais diretas, tendo em vista que o PIB do Nordeste é o mais crítico dentre as regiões do Brasil.

A dimensão ambiental, que também é alvo de muitas dificuldades na região, é superficialmente abordada nas diretrizes estratégicas das UFs, indicando área de preocupação para o alcance do desenvolvimento sustentável. A gestão das universidades deve ser sensibilizada a esse respeito, a fim de criar novas maneiras de abordar apropriadamente a questão.

Como limitação do estudo, aponta-se a possível lacuna entre o discurso e a prática, visto que não foi possível avaliar se as UFs efetivamente implementam as ações que indicam em seus planos. Além disso, as diretrizes estratégicas, apesar pouco para compreender toda a complexidade da vida universitária. Outra 
dificuldade foi a falta de padronização dos documentos institucionais que, por vezes, ainda estavam desatualizados, de acordo com as indicações do MEC.

Para estudos futuros, sugere-se investigações in loco para averiguar o contexto universitário de forma mais completa a fim de incorporar diferentes focos de análise. Outro foco de estudo seria a comparação do nível estratégico com o nível operacional (ações na prática, gestores, comissões, especialistas...), como por exemplo a existência de um Plano de Logística Sustentável, disciplinas focadas na educação para sustentabilidade ou atividades de extensão que promovam o desenvolvimento comunitário. 


\title{
Strategic perspective of sustainability in federal universities in the northeastern region of Brazil: an analysis through the triple bottom line
}

\begin{abstract}
The study's objective is to examine the perspective of sustainability, through the environmental, social and economic dimensions, in Institutional Development Plans (IDPs) of federal universities (FUs) of the northeastern region of Brazil. The research has qualitative and exploratory nature, and is operationalized through documentary research. The research technique was the content analysis, with a posteriori categorization of the data obtained from the Mission, Vision and Values of 16 FUs from the region. The results indicate that the social dimension of sustainability is broadly addressed in the strategic guidelines of the analyzed FUs, indicating good prospects for the role of Higher education institutions as tools of transformation. The economic dimension is moderately approached, being mentioned in an indirect way, as the development of professionals and the region. The environmental dimension is superficially addressed in the strategic guidelines of the FUs, indicating a field of concern for the achievement of sustainable development.
\end{abstract}

KEY WORDS: Sustainability in Universities; Education for Sustainability; Regional development; Northeast Region; Institutional Development Plan. 


\section{REFERÊNCIAS}

ALSHUWAIKHAT, Habib M.; ABUBAKAR, Ismaila. An integrated approach to achieving campus sustainability: assessment of the current campus environmental management practices. Journal Of Cleaner Production, China, v. 16, p.1777-1785, 2008.

ATLAS BRASIL. Atlas do Desenvolvimento Humano dos Municípios. <http://www.atlasbrasil.org.br/2013/>. Acesso em dez. 2017.

BARBIERI, José Carlos; SILVA, Dirceu da. Desenvolvimento sustentável e educação ambiental: uma trajetória comum com muitos desafios. RAM - Revista de Administração Mackenzie, v. 12, n. 3, 2011.

BARDIN, Laurence. Análise de conteúdo. São Paulo: Edições 70, 2016.

BARQUETTE, Stael., CHAOUBAH, Alfredo. Pesquisa de Marketing. São Paulo: Saraiva, 2007.

BRELSFORD, Christa; LOBO, José; HAND, Joe; BETTENCOURT, Luís. M. A. Proceedings of the National Academy of Sciences (PNAS), May 2017, 201606033; DOI:10.1073/pnas.1606033114.

CHAUÍ, Marilena. A universidade pública sob nova perspectiva. Revista Brasileira de Educação, v.24, pp.5-15, 2003.

ELKINGTON, John. Canibais com garfo e faca. São Paulo: M. Books do Brasil Editora, 2012.

FIGUEIRÓ, Paola Schmitt, RAUFFLET, Emmanuel. Sustainability in higher education: a systematic review with focus on management education. Journal of Cleaner Production, 2015.

GREENMETRIC. UI Green Metric World University Ranking on Sustainability. Disponível em < http://greenmetric.ui.ac.id/>. Acesso em nov. de 2017.

IBGE - Instituto Brasileiro de Geografia e Estatística. Indicadores de Desenvolvimento Sustentável. Brasil, 2015. 
IBGE - Instituto Brasileiro de Geografia e Estatística. Estimativas populacionais dos municípios, 2017. Disponível em :

<https://ww2.ibge.gov.br/home/estatistica/populacao/estimativa2017/estimativ a_dou.shtm>. Acesso em nov. 2017.

IBGE - Instituto Brasileiro de Geografia e Estatística. Síntese de Indicadores Sociais: uma análise das condições de vida. Estudos \& Pesquisas, 2017.

JACOBI, Pedro Roberto; RAUFFLET, Emmanuel; ARRUDA, Michelle Padovese de. Educação para a sustentabilidade nos cursos de Administração: reflexão sobre paradigmas e práticas. Revista de Administração. Mackenzie, v. 12, n. 3, 2011.

MARCOMIN, Fátima Elizabeti, SILVA, Aalberto Dias Vieira da. A sustentabilidade no ensino superior brasileiro: alguns elementos a partir da prática de educação ambiental na universidade. Contrapontos, v. 9, n. 2, p. 104-117, 2009.

MARCONI, Marina de Andrade, LAKATOS, Eva Maria. Fundamentos de Metodologia Científica, 8ª edição. Atlas, 2017.

MEC(a). Ministério da Educação. Qual é a diferença entre faculdades, centros universitários e universidades? Disponível em: < http://portal.mec.gov.br/pet/127-perguntas-frequentes-911936531/educacaosuperior-399764090/116-qual-e-a-diferenca-entre-faculdades-centrosuniversitarios-e-universidades>. Acesso em 05 dez. 2017.

MEC(b). Ministério da Educação. Instruções para elaboração de plano de desenvolvimento institucional. Disponível em:

<http://www2.mec.gov.br/sapiens/pdi.html>. Acesso em 05 dez. 2017.

MI - Ministério da Integração. Sistema Integrado de Informação sobre Desastres. Disponível em: <https://s2id.mi.gov.br/>. Acesso em dez. 2017.

MARQUES et al. Por que Sustentabilidade nos Cursos de Administração? In: PALMA, Lisiane Celia; NASCIMENTO, Luis Felipe; ALVES, Nilo Barcelo (organizadores). Educação para a sustentabilidade: bases epistemológicas, teorias e exemplos na área de Administração. Canoas, RS: IFRS - Campus Canoas, 2017. 
SILVA, Angelita Aparecida N. M.; CLARO, José Alberto C. S.; COSTA, Luciano Venelli; TINOCO, João Eduardo P. Gestão Ambiental e Universidade: Estudo de Caso do Programa Metodista Sustentável. Desenvolvimento em Questão, v. 13, p. 146-177, 2015.

TAUCHEN, Joel; BRANDLI, Luciana Londero. A gestão ambiental em instituições de ensino superior: modelo para implantação em campus universitário. Gestão \& Produção, v. 13, n. 3, p. 503 - 515, 2006.

TERMIGNONI, Luciana Dalfollo Ferreira. Framework de sustentabilidade para Instituições de Ensino Superior Comunitárias. Dissertação (Mestrado em Administração). Pontifícia Universidade Católica do Rio Grande do Sul, Porto Alegre, Brasil, 2012.

THOMASHOW, Mitchell. The nine elements of sustainable campus. USA: Massachusetts Institute of Technology, 2014.

ULSF. University Leaders for a Sustainable Future. The talloires declaration. France, 1990. Disponível em: <http://ulsf.org/talloiresdeclaration/ >. Acesso em nov. 2017.

VELAZQUEZ, Luiz. MUNGUIA, Nora; PLATT, Alberto; TADDEI, Jorge. Sustainable university: what can be the matter? Journal of Cleaner Production, v. 14, 2006.

VERGARA, Sylvia. Constant. Métodos de Pesquisa em Administração, 6a edição. Atlas, 2015.

WAAS, Tom; VERBRUGGEN, Aviel; WRIGHT, Tarah. University research for sustainable development: definition and characteristics explored. Journal of Cleaner Production, v. 18, p. 629-636, 2010. 
Recebido: 05 fev. 2020.

Aprovado: 28 mar. 2020.

DOI: $10.3895 /$ rbpd.v9n2.8907

Como citar: CASTRO, A. E.; ZWICKER, A. A. M.; KNEIPP, J. M.; LÖBLER, M. L.

Perspectiva estratégica da sustentabilidade nas universidades federais da região nordeste do Brasil: uma análise por meio do triple bottom line. R. bras. Planej. Desenv. Curitiba, v. 9, n. 2, p. 228-256, mai./ago. 2020.

Disponível em: <https://periodicos.utfpr.edu.br/rbpd>. Acesso em: XXX.

Correspondência:

Ana Amélia Moura Zwicke

Av. Roraima ํㅜ 1000 Cidade Universitária Bairro - Camobi - Santa Maria, RS

Direito autoral: Este artigo está licenciado sob os termos da Licença CreativeCommons-Atribuição 4.0

Internacional.

(c) (1) 